\title{
Effect of Delaying School Start Time on Sleep Quality, Emotions, and Performance in Korean Adolescents
}

\author{
Hayeon Kim, MD, Ji Hye Oh, MD, Sung Min Kim, MD, Yoo Hyun Um, MD, PhD, Ho Jun Seo, MD, PhD, \\ Jong-Hyun Jeong, MD, PhD, Seung-Chul Hong, MD, PhD, Tae Won Kim, MD \\ Department of Psychiatry, St. Vincent's Hospital, College of Medicine, The Catholic University of Korea, Suwon, Korea
}

\author{
Received: April 9, 2019 \\ Revised: June 2, 2019 \\ Accepted: June 11, 2019 \\ Correspondence \\ Tae Won Kim, MD \\ Department of Psychiatry, \\ St. Vincent's Hospital, \\ College of Medicine, \\ The Catholic University of Korea \\ 93 Jungbu-daero, Paldal-gu, \\ Suwon 16247, Korea \\ Tel +82-31-249-7150 \\ Fax +82-31-248-6758 \\ E-mail decontex@empas.com \\ ORCID \\ Hayeon Kim \\ https://orcid.org/0000-0002-7739-7152 \\ Ji Hye Oh \\ https://orcid.org/0000-0002-1935-4066 \\ Sung Min Kim \\ https://orcid.org/0000-0002-3082-4014 \\ Yoo Hyun Um \\ https://orcid.org/0000-0002-3403-4140 \\ Ho Jun Seo \\ https://orcid.org/0000-0003-1661-1394 \\ Jong-Hyun Jeong \\ https://orcid.org/0000-0003-3570-7607 \\ Seung-Chul Hong \\ https://orcid.org/0000-0003-0828-2906 \\ Tae Won Kim \\ https://orcid.org/0000-0003-2689-202X
}

Background and Objective The purpose of this study was to investigate the effect of delaying school start time on sleep quality, emotions, and performance in Korean adolescents.

Methods Data were collected in two months and 12 months after delaying school time, each using self-administered questionnaires for 238 students at a middle school in Gyeonggi province. Questionnaires consisted of demographic data and various sleep and emotion related scales, including the Pittsburgh Sleep Quality Index (PSQI). Students were divided into two groups, of increased or decreased total sleep time (TST).

Results In both groups, sleep duration, global PSQI score, and sleep efficiency significantly improved in 12 months, compared to two months' data. There was significant improvement in depression, stress, behavioral aggression, and verbal aggression in the increased TST group. The increased TST group showed advancement in subjective feeling of happiness, and number of times students are late for school, between baseline and 12 months. The decreased TST group showed significant differences between baseline and 12 months in seven categories of subjective life quality/ emotions in school, including subjective feeling of happiness, concentrating in classes, and anger.

Conclusions After school start time was delayed, many adolescent's TST relatively decreased on school nights. However, students whose TST increased, showed reduction in depression, stress, and behavioral/verbal aggression. Students whose TST decreased also reported reduced negative affect, and significant improvement in subjective emotions and school performance. Delaying school start time may be beneficial, in improving mental health and quality of life of students.

Sleep Med Res 2019;10(1):1-7

Key Words Adolescent, School time, Sleep quality, Depression, Emotion

\section{INTRODUCTION}

During adolescence, students experience changes in sleep/wake time on weekdays and weekends. Adolescents tend to experience later sleep onset and later wake time in daytime, that is not usually seen among children and older adults [1,2]. This sleep phase shift is probably a result of multiple factors, including changes in the intrinsic circadian timing system, and the homeostatic sleep system during adolescent development [3]. It is deeply related to melatonin, the nocturnal hormone, and is influenced by sleep behavior and the environment (lifestyle factors such as light, exercise, eating habits, social interactions, and etc.) [4]. In adolescence, the sleep-wake cycle shifts from $11 \mathrm{pm}$ to $8 \mathrm{am}$, so that sleep time is maintained, making it difficult to go to bed before $11 \mathrm{pm}$. This causes late-adolescent students to go to bed, later than early adolescents $[5,6]$. This change in bedtime is influenced by physical changes in puberty, and many researchers report that sleep deprivation is caused by delay in sleep, sleeping pressure rate, or in the homeostatic sleep drive, which is the biological trigger of sleep $[6,7]$. 
Nonetheless, adolescents are under pressure to meet increasing academic and social demands, especially in East Asia where the importance of academic success is heavily emphasized [8]. This social atmosphere leads to later sleep and earlier wake up times, and adolescents usually don't get enough sleep. The longer they stay awake, and the higher the pressure on their sleep, the harder it is to resist [9].

According to a study on Human Rights of Korean Children and Adolescents by the National Youth Policy Institute of Korea in 2013, many adolescents reported insufficient sleep. From fourth grade in elementary school to third grade in high school (age 10-18), mean sleep duration was seven hours, six minutes [10]. The rate of children and adolescents who responded, that they had insufficient sleep was $52.8 \%$ [10]. As many students consistently petitioned to delay school start time, education experts investigated actual conditions in schools in Gyeonggi province. As a result, $99 \%$ of middle schools had school starting hours before or after 8:30 am.

Meanwhile for students, sleep patterns on weekends are delayed, compared to weekdays. Hansen and colleagues studied sleep patterns, of fourth-year high school students on school days and during vacations [11]. According to sleep diary data, weekday wake up times on school days were 1.5 hour earlier compared to vacation weekdays. Consequently, school schedules and early school start time, are causing weekday sleep deprivation and weekend oversleeping. This leads to circadian timing disruption, and decreased daytime alertness levels in adolescents. So, it is possible that average adolescents, suffer from chronic sleep deprivation during weekdays.

The impact of chronic insufficient sleep in adolescents has been implied in various studies. Many adverse medical and mental issues are related to sleep deprivation, including drowsy driving-related crashes, cardiovascular disease, and metabolic disorders [12-14]. Decreased executive cognitive functions, such as learning and memory function impairment, academic performance, and motivation for learning were also identified as potential consequences of deficient sleep in adolescents. Students also have impairments in mood, behavioral control, and report increased tardiness and absenteeism [15-19]. Results suggest that sleep deprivation could be modified by delaying school start time, to improve sleep deprivation of adolescents.

Owens et al. [20] designed a study that enrolled high school students in Rhode Island, to examine the impact of a 30-minute delay in school start time on adolescents' sleep, mood, and behavior. Students showed increased sleep duration, later average wake time, and average bedtime on school nights became significantly earlier. The study also reported improvement in fatigue, motivation in schoolwork, sports, and socializing. In another study, Danner and Phillips [21] researched the impact of delayed school start time, as one hour delay in school time was initiated in Kentucky. The result showed increased hours of sleep, and decreased extra sleep hours on weekends.
Based on results of the study that later school hours enhance the quality of students' school life as discussed earlier, the Gyeonggi Provincial Office of Education recommended that all schools start at 9:00 am in September 2014. As the previous school start time was 8:20 am, school attendance time was delayed 40 minutes.

The purpose of this study was to investigate the impact of delaying school start time on adolescent's sleep quality, emotions, and performance in school; in short term and long term follow up.

\section{METHODS}

\section{Participants and Study Design}

Subjects that participated in this study, were from a middle school in Gyeong-gi Province. We conducted two surveys: the first survey was conducted in November 2014, two months after the delay of school start time. The second survey was conducted in September 2015, 12 months after the delay of school start time. By conducting two surveys, we intended to examine short-term and long-term effects, after policy implementation. Students were given one week, to respond to each survey.

A longitudinal, observational study was accomplished with a self-administered, structured questionnaire that contained socio-demographic data, Pittsburgh Sleep Quality Index (PSQI), subscales of School Sleep Habits Survey (SSHS) (Sleepiness Scale, Depressed Mood Scale, Sleep/Wake Problems Behavior Scale), Perceived Stress Scale (PSS), Positive Affect and Negative Affect Schedule (PANAS), Satisfaction With Life Scale, and Anger Coping Scale (SWLS). We also included the Visual Analogue Scale (VAS) of subjective feeling of happiness, number of breakfasts eaten per week, number of times tardy at school per week, sleepiness during classes, concentration in classes, relationships with friends, energy in daily life, general feeling in school, willingness to attend school, anger, and suicidal ideation.

Sample size was 263 students. We excluded students who didn't complete the survey. Finally, 238 students completed questionnaires. In this study, we divided students into two groups whose total sleep time (TST) difference between two months follow up and 12 months follow up, decreased or increased by more than 20 minutes. We hypothesized that there will be changes in sleep patterns and school life according to increase or decrease in TST, over a certain period after delay of school starting hours.

The number of decreased TST group was 128 (53.8\%) and in the increased TST group, the number was 55 (23.1\%). Fiftyfive students (23.1\%) whose TST difference was plus-minus five minutes, were considered "equal."

This study was approved by the Institutional Review Board (IRB) of St. Vincent's Hospital, Suwon, Republic of Korea. The IRB granted a waiver of documentation of consent in this study (Study No. VC15QISI0192). 


\section{Measures}

\section{Pittsburgh Sleep Quality Index}

PSQI is a self-rated scale, to evaluate sleep quality and disturbances over a one-month interval in adults. It consists of seven components: 1) Subjective sleep quality, 2) Sleep latency, 3) Sleep duration, 4) Habitual sleep efficiency, 5) Sleep disturbances, 6) Use of sleeping medications, and 7) Daytime dysfunction. The first four questions are open question forms, and the last three items are 0-3 Likert-type scale. Lower scores indicate healthier sleep quality, and five or greater scores indicate poor sleep quality [22]. A study confirmed that the Korean version of PSQI is useful [23].

\section{School Sleep Habits Survey}

SSHS is a 63-item questionnaire, designed to assess sleep/ wake habits and typical daytime functioning of high school students. This scale distinguishes sleep habits in sub categories 1) Depressed Mood Scale, 2) Sleepiness Scale, 3) Sleep/Wake Problems Behavior Scale, and 4) The Superscience Morningness/Eveningness Scale. In this study, we used three subscales of SSHS: Depressed Mood Scale, Sleepiness Scale, and Sleep/Wake Problems Behavior Scale [24].

\section{Perceived Stress Scale}

PSS consists of a 10-question, self-administered inventory, widely used for measuring psychological stress [25]. In Korea, a 10-item version of PSS was reliable, and was validated in patients with chronic disease [26].

\section{Positive Affect and Negative Affect Schedule}

PANAS is a self-report instrument that measures two general dimensions, positive and negative affect. There are two versions of the questionnaire: a 60 -item version (PANAS-X) and a brief 20 -item scale. Participants rate how they feel for each adjective on a 5-point scale ranging from 1 (very slightly) to 5 (extremely) [27]. High Positive Affect (PA) scores mean high energy concentration, and low PA is distinguished as sadness and lethargy. Negative Affect reflects calmness and tranquility. In this study, we adopted the brief version of PANAS. The Korean version of PANAS was validated by a study [28].

\section{Satisfaction with Life Scale}

SWLS is a five-item scale, which focuses on assessing global life satisfaction in people experiencing serious health concerns. Scores of SWLS are highly related to subjective well-being [29]. The instrument, is a 7-point Likert style response scale. Range of scores is 5-35, with a score of 20-24 representing an average satisfaction. Scores between 5-9 indicate the respondent is extremely dissatisfied with life, and a score of 30-35 indicate that respondents are in a highly satisfied condition [30]. To examine reliability of the scale in Korean students, a validation study was conducted, and was proven to be effective [31].

\section{Anger Coping Scale}

Anger Coping Scale was formulated for Koreans based on the concept that the method of responding to anger varies among different cultures. The measure comprises 19 questions in five sub categories: 1) Behavioral aggression, 2) Problem-solving coping, 3) Verbal aggression, 4) Tension releasing coping, and 5) Anger suppression. Meanwhile, the survey consisted of a 5-point scale that required participants to respond to 'Never' ( 0 points), 'Rarely' (1 points), 'Occasionally' ( 2 points), 'Almost always' (3 points), and 'Every time' (4 points) [32].

\section{Statistical Analysis}

Statistical analyses were performed, with the Statistical Package for Social Sciences software (SPSS, version 21.0, IBM Corp., Armonk. NY, USA). Mann-Whitney U test was used to measure differences between decreased TST, and increased TST groups, for all demographic variables. To evaluate differences between two-month and 12-month data in each group, we used the Wilcoxon signed rank test. All statistical analyses used a two-tailed a level of 0.05 , for defining statistical significance.

\section{RESULTS}

\section{Demographic Data}

Table 1 shows basic demographic data in our two different groups. The Mann-Whitney $U$ test was used to assess if there is a difference between the two groups, in the two-month follow up data and one-year follow up data. This study revealed 55 (23.1\%) of students in the increased TST group, 128 (53.8\%) students in the decreased TST group, and 55 (23.1\%) in the equal TST group. Eighty-five participants were male. The study was conducted on age 13-14 students. Sex and Body Mass Index differences, were not statistically significant.

\section{Differences in School Nights and Weekend Nights}

Table 2 shows self-reported bedtime, wake time, and TST on school nights and weekend nights. On school nights, wake time and TST were significantly different for 12 months follow up data, compared to two months follow up data in both groups. Wake time was delayed to 7:45 am in the increased TST group $(\mathrm{p}=0.002)$, and TST increased from $7.4 \pm 1.3$ hours to $8.0 \pm$ 1.2 hours in 12 months follow up ( $\mathrm{p}=0.002)$. In the decreased TST group, bedtime was significantly delayed from 11:32 pm to $12: 06$ am $(\mathrm{p}<0.001)$. Mean wake time became significantly earlier from 7:35 am to 7:26 am ( \pm 44 minutes) $(p=0.003)$, and TST decreased from $8.1 \pm 0.9$ hours to $7.3 \pm 1.1$ hours ( $\mathrm{p}$ $<0.001$ ).

On weekend nights, the increased TST group had no significant differences between short- and long-term follow up. 
Meanwhile, in the decreased TST group, weekend bedtime was delayed to $12: 47$ am ( \pm 1 hour 17 minutes) ( $\mathrm{p}<0.001)$, and TST time also was reduced to $8.7 \pm 1.5$ hours $(\mathrm{p}<0.001)$.

Overall, students whose TST increased after the policy, awoke later on school days, and kept their sleep patterns on weekend nights. Students who slept less tended to sleep later, waking up earlier. This sleep pattern was maintained on weekend nights.

\section{Findings in Sleep Parameters and Emotions}

Table 3 shows differences of sleep-related parameters and school day emotions, between two months and 12 months follow up by each group. In the increased TST group, PSQI sleep duration ( $0.9 \pm 0.8$ vs. $0.5 \pm 0.6, \mathrm{p}<0.001)$, global PSQI score $(6.2 \pm 3.4$ vs. $5.3 \pm 2.8, \mathrm{p}=0.049)$, sleep efficiency $(87.0 \pm 9.8$ vs. $96.8 \pm 6.7, \mathrm{p}<0.001)$ had significant differences in 12 months. Also, scores in the Depressed Mood Scale of SSHS (8.6 \pm 2.2 vs. $8.0 \pm 2.0, \mathrm{p}=0.045)$ and PSS-10 (14.6 \pm 6.7 vs. $12.9 \pm 5.8, \mathrm{p}$ $=0.038)$ was significantly reduced. There was significant difference of behavior aggression $(1.4 \pm 2.0$ vs. $0.9 \pm 1.9, \mathrm{p}=0.006)$ and verbal aggression $(4.5 \pm 3.3$ vs. $3.4 \pm 3.0, \mathrm{p}=0.015)$, that are subscales of the Anger Coping Scale.

Table 1. Demographic data of the two-months follow study

\begin{tabular}{lcccc}
\hline & Increased TST $(\mathrm{n}=55)$ & Decreased TST $(\mathrm{n}=128)$ & Equal TST $(\mathrm{n}=55)$ & Total $(\mathrm{n}=238)$ \\
\hline Age & $13.7 \pm 0.5$ & $13.3 \pm 0.5$ & $13.5 \pm 0.5$ & $13.5 \pm 0.5$ \\
Sex $(\mathrm{M} / \mathrm{F})$ & $23 / 32$ & $62 / 66$ & $23 / 32$ & $108 / 130$ \\
$\mathrm{BMI}\left(\mathrm{kg} / \mathrm{m}^{2}\right)$ & $19.3 \pm 2.6$ & $19.4 \pm 3.1$ & $18.8 \pm 2.5$ & $19.3 \pm 2.8$ \\
\hline
\end{tabular}

Analyzed by chi-square test, and Mann-Whitney U test.

TST: total sleep time, BMI: Body Mass Index.

Table 2. Mean self-reported bedtimes, wake times and sleep duration on school nights and weekend nights

\begin{tabular}{|c|c|c|c|c|}
\hline & \multicolumn{2}{|c|}{ Increased TST $(\mathrm{n}=55)$} & \multicolumn{2}{|c|}{ Decreased TST $(n=128)$} \\
\hline & 2 months & 12 months & 2 months & 12 months \\
\hline \multicolumn{5}{|l|}{ School nights } \\
\hline Bedtime & $12: 02$ am (1:15) & $11: 47$ pm $(0: 56)$ & $11: 32 \mathrm{pm}(0: 50)$ & $12: 06$ am $(1: 03)^{*}$ \\
\hline Wake time & $7: 25$ am $(0: 28)$ & 7:45 am $(1: 04)^{*}$ & $7: 35$ am $(0: 32)$ & $7: 26$ am $(0: 44)^{*}$ \\
\hline TST (hour) & $7.4(1.3)$ & $8.0(1.2)^{*}$ & $8.1(0.9)$ & $7.3(1.1)^{*}$ \\
\hline \multicolumn{5}{|l|}{ Weekend nights } \\
\hline Bedtime & $12: 20$ am (1:34) & $12: 34$ am (1:12) & $12: 11$ am $(1: 21)$ & $12: 47$ am $(1: 17)^{*}$ \\
\hline Wake time & $9: 36$ am $(2: 21)$ & $9: 46$ am $(2: 17)$ & $9: 32$ am (1:24) & $9: 27$ am (1:26) \\
\hline TST (hour) & $9.0(1.9)$ & $9.2(2.3)$ & $9.3(1.5)$ & $8.7(1.5)^{*}$ \\
\hline
\end{tabular}

Data are expressed as mean (SD). For bedtimes and wake times, the standard deviations are expressed as hours:minutes.

*Significantly different from the 2 month data $(\mathrm{p}<0.05)$.

TST: total sleep time.

Table 3. Mean differences of sleep related parameters and emotions in increased or decreased TST groups

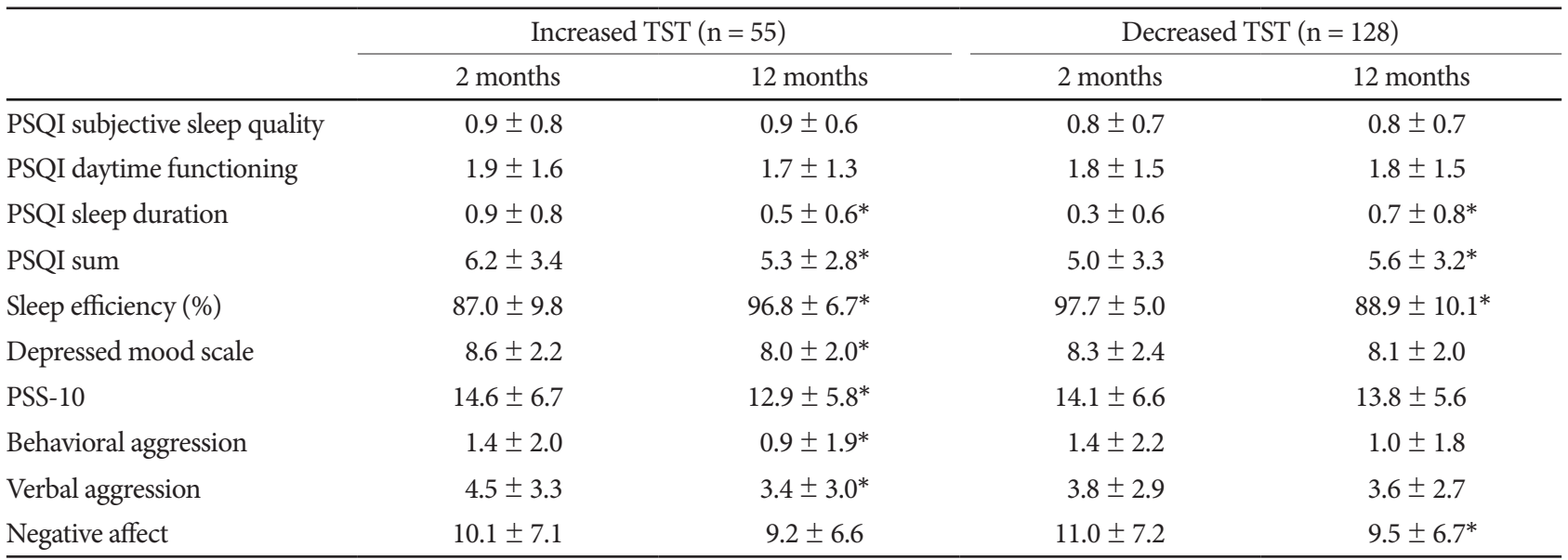

Data are expressed as mean \pm SD. Analyzed by Wilcoxon signed rank test.

*Significantly different from 2 month data $(\mathrm{p}<0.05)$.

PSQI: Pittsburgh Sleep Quality Index, TST: total sleep time, PSS: Perceived Stress Scale. 
In the decreased TST group, PSQI sleep duration $(0.3 \pm 0.6$ vs. $0.7 \pm 0.8, \mathrm{p}<0.001)$, global PSQI score ( $5.0 \pm 3.3$ vs. $5.6 \pm$ $3.2, p=0.004)$, and sleep efficiency (97.7 \pm 5.0 vs. $88.9 \pm 10.1$, $\mathrm{p}<0.001$ ) had significant differences in one year follow up. Differences in the Depressed Mood Scale, PSS-10, behavior aggression, and verbal aggression were not significant in the decreased TST group, but negative affect was significantly reduced $(11.0 \pm 7.2$ vs. $9.5 \pm 6.7, \mathrm{p}=0.036)$.

\section{School Attendance, Subjective School Life Quality, and Emotions}

Students were required to respond, to the VAS of emotions related to school activities. For example, a subjective feeling of happiness was graded from 1 (very much unhappy) to 10 (very much happy). Number of breakfasts eaten per week, and tardiness at school per week were graded 1 to 7 .

Table 4 shows that in each group, emotions and behavior in school changed, as students adapted to a later school start time. Differences in subjective school life quality and emotion parameters measured in VAS between the baseline, two-month follow up, and 12-month follow up data are presented. In the increased TST group, two-month happiness was significantly greater than the baseline $(6.9 \pm 2.0$ vs. $6.2 \pm 2.0, \mathrm{p}=0.008)$. Also, the two-month number relative to tardiness, was significantly lower than the baseline $(1.2 \pm 1.5$ vs. $1.6 \pm 1.7, \mathrm{p}=0.035)$.

In the decreased TST group, subjective feeling of happiness in two months $(7.0 \pm 2.2)$ and 12 months $(7.1 \pm 1.9)$ was significantly greater than the baseline $(5.9 \pm 2.2, \mathrm{p}<0.001, \mathrm{p}<$ $0.001)$. Number of breakfasts eaten per week also increased in two-month follow up (5.5 \pm 2.2$)$ and 12-month follow up (5.5 $\pm 2.0)$ compared with the baseline $(5.0 \pm 2.4, \mathrm{p}<0.001, \mathrm{p}=$ 0.005 ). Tardiness occurrence at school was significantly lower in two-month (1.1 \pm 1.7$)$ and 12-month (1.1 \pm 1.1$)$ follow up, than the baseline $(1.3 \pm 1.6, \mathrm{p}=0.026, \mathrm{p}=0.045)$. Sleepiness during classes decreased in two-month (4.2 \pm 2.8$)$ and 12-month (4.2 \pm 2.3$)$ follow up, compared with the baseline ( $5.1 \pm 3.0$, $\mathrm{p}$ $<0.001, \mathrm{p}=0.006)$. Concentration in classes in two-month follow up (6.5 \pm 2.6$)$ and 12-month follow up $(6.9 \pm 1.9)$ was significantly greater than the baseline $(5.9 \pm 2.4, \mathrm{p}<0.001, \mathrm{p}<$ $0.001)$. Relationships with friends was $7.4 \pm 2.4$ in the baseline and $7.9 \pm 2.1$ in two-month follow up, shows significant difference $(p=0.005)$. Energy in daily life score was $6.9 \pm 2.3$ in the baseline, and $7.6 \pm 2.0$ in two-month follow up ( $<<0.001)$. Students' responses show that the general feeling in school was significantly better in two-month $(7.2 \pm 2.1)$ and 12 -month $(7.3 \pm 2.0)$ follow up, than the baseline happiness ( $6.8 \pm 2.2, \mathrm{p}$ $=0.001, \mathrm{p}=0.030$ ). Also, willingness to attend school significantly increased from the baseline to two-month follow up (6.2 \pm 2.5 vs. $6.6 \pm 2.4, p<0.001$ ). Anger significantly decreased in only 12 -month follow up, compared to the baseline $(3.2 \pm 1.8$ vs. $4.0 \pm 2.2, \mathrm{p}=0.003)$.

\section{DISCUSSION}

In this study, we revealed the effect of delaying school start time of Korean adolescents on their sleep quality, emotions, and performance. The school start time was delayed from 8:20 am to 9:00 am in the sample school, which was a 40-minute delay. In this study, we divided students into two groups, according to increase and decrease of TST, between two and 12 months. We assumed that physiological sleep phase shift in adolescents, may have caused chronic sleep deprivation. We speculated that if school start time is delayed, many adoles-

Table 4. School attendance, subjective school life quality and emotion parameters measured in VAS in adolescents with baseline, 2 months follow up and 12 months follow up

\begin{tabular}{|c|c|c|c|c|c|c|}
\hline & \multicolumn{3}{|c|}{ Increased TST $(\mathrm{n}=55)$} & \multicolumn{3}{|c|}{ Decreased TST $(\mathrm{n}=128)$} \\
\hline & Baseline & 2 months & 12 months & Baseline & 2 months & 12 months \\
\hline Subjective feeling of happiness & $6.2 \pm 2.0$ & $6.9 \pm 2.0^{*}$ & $6.8 \pm 2.1$ & $5.9 \pm 2.2$ & $7.0 \pm 2.2^{*}$ & $7.1 \pm 1.9^{\dagger}$ \\
\hline Number of eating breakfast & $5.4 \pm 2.2$ & $5.5 \pm 2.0$ & $5.8 \pm 1.8$ & $5.0 \pm 2.4$ & $5.5 \pm 2.2^{*}$ & $5.5 \pm 2.0^{\dagger}$ \\
\hline Number of being late for school & $1.6 \pm 1.7$ & $1.2 \pm 1.5^{*}$ & $1.1 \pm 1.3$ & $1.3 \pm 1.6$ & $1.1 \pm 1.7^{*}$ & $1.1 \pm 1.1^{\dagger}$ \\
\hline Sleepiness during class & $4.4 \pm 2.7$ & $4.4 \pm 2.3$ & $4.4 \pm 2.5$ & $5.1 \pm 3.0$ & $4.2 \pm 2.8^{*}$ & $4.2 \pm 2.3^{\dagger}$ \\
\hline Concentration on class & $5.9 \pm 2.9$ & $6.4 \pm 2.6$ & $6.7 \pm 2.3$ & $5.9 \pm 2.4$ & $6.5 \pm 2.6^{*}$ & $6.9 \pm 1.9^{\dagger}$ \\
\hline Relationship with friends & $8.7 \pm 10.0$ & $7.7 \pm 2.2$ & $7.8 \pm 2.1$ & $7.4 \pm 2.4$ & $7.9 \pm 2.1^{*}$ & $7.8 \pm 1.9$ \\
\hline Energy in daily life & $7.0 \pm 2.4$ & $7.4 \pm 2.3$ & $7.1 \pm 2.0$ & $6.9 \pm 2.3$ & $7.6 \pm 2.0^{*}$ & $7.3 \pm 2.1$ \\
\hline General feeling in school & $7.0 \pm 2.5$ & $7.3 \pm 2.3$ & $7.2 \pm 2.0$ & $6.8 \pm 2.2$ & $7.2 \pm 2.1^{*}$ & $7.3 \pm 2.0^{\dagger}$ \\
\hline Willingness to go to school & $6.4 \pm 2.6$ & $6.7 \pm 2.5$ & $6.7 \pm 2.5$ & $6.2 \pm 2.5$ & $6.6 \pm 2.4^{*}$ & $6.5 \pm 2.4$ \\
\hline Anger & $3.3 \pm 2.3$ & $3.3 \pm 2.3$ & $3.1 \pm 1.9$ & $4.0 \pm 2.2$ & $3.7 \pm 2.2$ & $3.2 \pm 1.8^{\dagger}$ \\
\hline Suicidal ideation & $2.0 \pm 1.9$ & $2.0 \pm 2.0$ & $1.8 \pm 1.4$ & $2.1 \pm 2.1$ & $2.1 \pm 2.1$ & $1.7 \pm 1.5$ \\
\hline
\end{tabular}

Data are expressed as mean \pm SD.

*Significantly different from baseline $(\mathrm{p}<0.05)$. ${ }^{\dagger}$ Significantly different from baseline $(\mathrm{p}<0.05)$.

VAS: Visual Analogue Scale, TST: total sleep time. 
cents would benefit from sleep duration, reduce health related problems, and improve school performance.

In our study, results showed that of 238 students (total) who responded to the questionnaire, 128 had decrease in TST after 10 months, and 55 had TST increase of more than 20 minutes. This differs from results of other studies postulating, that adolescents have generally increased sleep time after delaying school start time [33-35]. According to our results, more than half of the students sleep less in 12 months, compared to two months after delaying school start time. It is likely to be related to survey timing, or seasonal factor of the study. It could be also related to different school years, of the two surveys. All the students became seniors, which may have caused sleep deprivation because of more academic pressure. Table 2 also shows students' bedtime is $30-40$ minutes delayed, but wake-up time is two hours delayed on weekends. Although school start time was delayed, students may have had sleep deprivation on school nights.

In the decreased TST group, even if TST on weekdays decreased and global PSQI score, sleep efficiency worsened in 12-month follow up, the negative affect showed improvement. They wake up earlier, but since they have time to spare until school starts, their satisfaction level in school life seems to increase. In the increased TST group, improvement in global PSQI score and sleep efficiency, as well as advanced depression, stress, and behavioral/verbal aggression was remarkable. This may have positive effects, on sense of well-being of adolescents. Because the number of tardy days at school is included in school reports, early school start time would have been stressful for students.

VAS score was applied, to evaluate subjective feelings related to school activities. The questionnaire was designed to measure the feelings in early school hour days before the policy was implemented, and current feelings and performance. In two-month follow-up data, we discovered how students subjectively felt about changes in school start time and their school life in two and 12 months, compared to the baseline. This also showed how students remembered their old days, compared to present school life, retrospectively. In this study, two months' improvement in subjective feeling of happiness and number of tardy days at school, was significant in the increased TST group. However, students did not feel significant differences in school life in the 12-month follow up study. This may indicate that students experienced rapid improvement in the early period after adjustment to school start time, and long-term studies have shown that they adapted to these changes. Students whose TST decreased also had experienced improvement in emotions and performance in school in most of the subscales, and these subjective feelings prevailed in long-term follow up. Adolescents showed significant improvement in anger management after 12 months, suggesting that improvement in anger management did not change in early stages, but was significant in later stages. Overall, according to the VAS, distress in school life was reduced in both groups.

The strength of this study is that the outcome supports previous studies that reported after school start time was delayed, many adolescents' emotions and behavior in school improved $[20,33,36]$. Also, to our knowledge, there has been scant research, on sleep time of adolescents in South Korea. As school culture in East Asia heavily emphasizes the importance of academic achievement, it is significant to reveal changes in school life when school start time is delayed [8]. This study is meaningful in that it analyzed short-term and long-term effects after policy implementation, as it was conducted twice in a group with a large population after two months and 12 months, respectively.

This study has limitations. First, we recruited all subjects from one institution only, so the result may have limitations relative to generalizations. Second, it was difficult to obtain sufficient data on the baseline, because delaying school start time was abruptly decided. Specifically, students with reduced TST slept longer in two months (8.1 \pm 0.9 hours), than those with increased sleep $(7.4 \pm 1.3)$. We lack data on previous sleep duration before changing the school start time, so this study is limited in asserting reasons for the change in TST over time.

In future studies, it will be crucial to assess long-term outcomes in middle and high schools, which adopted the policy of delaying school time. Broader studies are possible using a variety of sleep or depression, anxiety, and stress-related measures. Results of this study could support previous studies reporting benefits of adjusting school start time for adolescents' circadian rhythm, sleep needs in the developmental stage, performance in school, and quality of life. Since this study has laid the groundwork for long-term benefits after policy implementation, it should be possible to further strengthen this evidence through larger, longer-term studies.

\section{Conflicts of Interest}

The authors have no financial conflicts of interest.

\section{Authors' Contribution}

Conceptualization: Kim T, Hong S, Jeong J. Data curation: Kim H, Kim T, Hong S. Formal analysis: Kim H, Kim T, Seo H. Project administration: Kim T, Hong S. Resources: Kim T, Hong S. Supervision: Kim T. Validation: Kim T. Writing—original draft: Kim H. Writing—review \& editing: Kim T, Um Y, Oh J, Kim S.

\section{REFERENCES}

1. Carskadon MA. Patterns of sleep and sleepiness in adolescents. Pediatrician 1990;17:5-12.

2. Dahl RE CM. Sleep and its disorders in adolescence. In: Ferber R KM. Principles and Practice of Sleep Medicine in the Child. Philadelphia: WB Saunders 1995;19-27.

3. Carskadon MA, Wolfson AR, Acebo C, Tzischinsky O, Seifer R. Adolescent sleep patterns, circadian timing, and sleepiness at a transition to early school days. Sleep 1998;21:871-81.

4. Saper CB, Lu J, Chou TC, Gooley J. The hypothalamic integrator for 
circadian rhythms. Trends Neurosci 2005;28:152-7.

5. Andrade MM, Benedito-Silva AA, Domenice S, Arnhold IJ, MennaBarreto L. Sleep characteristics of adolescents: a longitudinal study. $J$ Adolesc Health 1993;14:401-6.

6. Carskadon MA, Vieira C, Acebo C. Association between puberty and delayed phase preference. Sleep 1993;16:258-62.

7. Hagenauer MH, Perryman JI, Lee TM, Carskadond MA. Adolescent changes in the homeostatic and circadian regulation of sleep. Dev Neurosci 2009;31:276-84.

8. Stankov L. Unforgiving Confucian culture: a breeding ground for high academic achievement, test anxiety and self-doubt? Learn Individ Differ 2010;20:555-63.

9. Mindell JA, Owens JA. A clinical guide to pediatric sleep: diagnosis and management of sleep problems. Philadelphia, PA: Lippincott Williams \& Wilkins 2003.

10. Kim YJ, Kim KJ, Choi YH, Yoo SH. The study on the current status of Korean children's and youth's rights III. Seoul: National Youth Policy Institute of Korea 2013. Available at: https://www.nypi.re.kr/brdrr/ boardrrView.do?menu_nix=4o9771b7\&brd_id=BDIDX_PJk7xvf7L09 $6 \mathrm{~m} 1 \mathrm{~g} 7 \mathrm{Phd} 3$ YC\&cont_idx=458\&seltab_idx=08edomweivgp=R.

11. Hansen M, Janssen I, Schiff A, Zee PC, Dubocovich ML. The impact of school daily schedule on adolescent sleep. Pediatrics 2005;115:155561.

12. Verhulst SL, Schrauwen N, Haentjens D, Rooman RP, Van Gaal L, De Backer WA, et al. Sleep duration and metabolic dysregulation in overweight children and adolescents. Arch Dis Child 2008;93:89-90.

13. Dahl RE. Biological, developmental, and neurobehavioral factors relevant to adolescent driving risks. Am J Prev Med 2008;35(3 Suppl):S27884.

14. Gangwisch JE, Malaspina D, Babiss LA, Opler MG, Posner K, Shen S, et al. Short sleep duration as a risk factor for hypercholesterolemia: analyses of the National longitudinal study of adolescent health. Sleep 2010;33:956-61.

15. Curcio G, Ferrara M, De Gennaro L. Sleep loss, learning capacity and academic performance. Sleep Med Rev 2006;10:323-37.

16. Fredriksen K, Rhodes J, Reddy R, Way N. Sleepless in Chicago: tracking the effects of adolescent sleep loss during the middle school years. Child Dev 2004;75:84-95.

17. Perkinson-Gloor N, Lemola S, Grob A. Sleep duration, positive attitude toward life, and academic achievement: the role of daytime tiredness, behavioral persistence, and school start times. J Adolesc 2013;36:311-8.

18. Wolfson AR, Carskadon MA. Understanding adolescents' sleep patterns and school performance: a critical appraisal. Sleep Med Rev 2003; 7:491-506.

19. Pasch KE, Laska MN, Lytle LA, Moe SG. Adolescent sleep, risk behaviors, and depressive symptoms: are they linked? Am J Health Behav 2010;34:237-48.
20. Owens JA, Belon K, Moss P. Impact of delaying school start time on adolescent sleep, mood, and behavior. Arch Pediatr Adolesc Med 2010; 164:608-14.

21. Danner F, Phillips B. Adolescent sleep, school start times, and teen motor vehicle crashes. J Clin Sleep Med 2008;4:533-5.

22. Buysse DJ, Reynolds CF 3rd, Monk TH, Berman SR, Kupfer DJ. The Pittsburgh Sleep Quality Index: a new instrument for psychiatric practice and research. Psychiatry Res 1989;28:193-213.

23. Sohn SI, Kim DH, Lee MY, Cho YW. The reliability and validity of the Korean version of the Pittsburgh Sleep Quality Index. Sleep Breat 2011; 16:803-12.

24. Wolfson AR, Carskadon MA, Acebo C, Seifer R, Fallone G, Labyak SE, et al. Evidence for the validity of a sleep habits survey for adolescents. Sleep 2003;26:213-6.

25. Cohen S, Kamarck T, Mermelstein R. A global measure of perceived stress. J Health Soc Behav 1983;24:385-96.

26. Lee EH, Chung BY, Suh CH, Jung JY. Korean versions of the Perceived Stress Scale (PSS-14, 10 and 4): psychometric evaluation in patients with chronic disease. Scand J Caring Sci 2015;29:183-92.

27. Watson D, Clark LA, Tellegen A. Development and validation of brief measures of positive and negative affect: the PANAS scales. J Pers Soc Psychol 1988;54:1063-70.

28. Lim YJ, Yu BH, Kim DK, Kim JH. The positive and negative affect schedule: psychometric properties of the Korean version. Psychiatry Investig 2010;7:163-9.

29. Diener E, Emmons RA, Larsen RJ, Griffin S. The Satisfaction With Life Scale. J Pers Assess 1985;49:71-5.

30. Pavot W, Diener E. The Satisfaction With Life Scale and the emerging construct of life satisfaction. J Posit Psychol 2008;3:137-52.

31. Lim YJ. Psychometric characteristics of the Korean version of the Satisfaction With Life Scale adapted for children. Can J Sch Psychol 2015; 30:246-51.

32. Koh KB , Park JK. Development of the Anger Coping Scale. J Korean Neuropsychiatr Assoc 2005;44:477-88.

33. Boergers J, Gable CJ, Owens JA. Later school start time is associated with improved sleep and daytime functioning in adolescents. J Dev Behav Pediatr 2014;35:11-7.

34. Brandalize M, Pereira RF, Leite N, Filho GL, Louzada FM. Effect of morning school schedule on sleep and anthropometric variables in adolescents: a follow-up study. Chronobiol Int 2011;28:779-85.

35. Brown RS, Presley A, Newton L, Davison C. Eastern Commerce Collegiate Institute's Late Start: year one interim report. Etobicoke (ON): Toronto District School Board 2011.

36. Lo JC, Lee SM, Lee XK, Sasmita K, Chee N, Tandi J, et al. Sustained benefits of delaying school start time on adolescent sleep and well-being. Sleep 2018;41(6). 